\title{
COMPARISON BETWEEN TWO TREATMENT PROTOCOLS FOR COMPLETELY EDENTULOUS MAXILLA OPPOSING MANDIBULAR KENNEDY CLASS I
}

\author{
Shaimaa Lotfy * and Yasmine G. Thabet *
}

\begin{abstract}
Objectives: This research was carried out to determine whether mandibular implant supported overdenture or maxillary implant supported overdenture is more effective in prevention of combination syndrome.

Materials and Methods: Totally, fourteen patients with completely edentulous upper arch and mandibular bilateral distal extensions (Kennedy class I) with the canines or first premolar as the last standing tooth were selected to participate in this study. Inclusion criteria: Patients had wellformed residual ridge covered with dense fibrous connective tissue, Angle class I ridge relationship, and adequate inter arch space. Patients with systemic diseases that might affect the oral tissues or bone, neuromuscular disorders, temporomandibular joint disorders and smokers were excluded. Patients were randomly divided into two equal groups, Group I: patients were rehabilitated with mucosa supported maxillary complete denture and lower tooth-implant partial denture retained by two osseointegrated implants on each side of the lower arch in the first molar area and RPI direct retainer. Group II: patients were rehabilitated with implant retained and supported maxillary complete overdenture by four osseointegrated implants in the anterior maxillary area and toothtissue supported partial denture retained by RPI direct retainer. In this study, marginal bone height changes in the premaxillary region and mucosal thickness at the crest of maxillary ridge were evaluated at the time of prostheses insertion, six, twelve and eighteen months.
\end{abstract}

Results: In this study, an insignificant difference was detected between the two groups at the different follow-up intervals, regarding marginal bone loss and mucosal thickness. After 18 months follow up, bone loss \& mucosal thickness were $0.5 \pm 0.2,0.6 \pm 0.3 \mathrm{~mm}$ for group I and $0.5 \pm 0.2$, $0.3 \pm 0.2 \mathrm{~mm}$ for group II respectively. Although group II showed decrease in marginal bone loss and decrease in mucosal thickness compared to group I however difference between groups were statistically insignificant.

Conclusion: Within the limitations of the number of studied patients and follow up period of this study it could be concluded that, preventing the degenerative oral changes that occurs when complete maxillary dentures opposes the Kennedy class I partial dentures may be possible through accurate treatment planning and, the development of stable posterior occlusion that controls of occlusal pressures on the anterior maxilla. Also, maxillary implant retained overdentures should be considered preferable treatment option, whenever the available bone quantity and quality permits.

KEY WORDS: Maxillary edentulous arch, Kennedy class I, dental implant, marginal bone height and mucosal thickness.

* Lecturer of Removable Prosthodontics, Faculty of Dentistry Ain Shams University. 


\section{INTRODUCTION}

Management of patients with completely edentulous maxilla opposing mandibular Kennedy class I is considered very challenging. This may be attributed to the excessive traumatic forces that could lead to destruction of both the maxilla and the mandible. The characteristic features that commonly occur in these cases were described as the combination syndrome.

According to the "Glossary of Implant Terms" combination syndrome is defined as "A condition caused by the presence of lower anterior teeth and an absence of the posteriors, resulting in significant maxillary anterior alveolar resorption". (1)

The characteristic features that occur include bone loss in the anterior part of the maxillary ridge, enlargement of the tuberosities, papillary hyperplasia of the hard palate, extrusion of the lower anterior teeth, and bone loss in the posterior part of the mandibular edentulous ridge. ${ }^{(2)}$ Moreover, occlusal vertical dimension is reduced, occlusal plane is disrupted, the mandible becomes anteriorly repositioned, and adaptation of the prostheses diminishes. Epulis fissuratum and periodontal changes were also detected. ${ }^{(3)}$

These changes were attributed to multiple factors and several theories were proposed to explain the sequence and the causes of the combination syndrome. Kelly assumed that presence of the lower anterior teeth directs excessive functional and para-functional forces to the anterior part of the maxilla. This results in early bone loss in the premaxilla which is the key to the other changes of the combination syndrome. Consequently, flabby hyperplastic connective tissues make up the anterior part of the ridge. The second important sign in combination syndrome is enlargement of maxillary tuberosities which was caused by "negative pressure" from underneath the denture due to presence of a posterior palatal seal. ${ }^{(4)}$
Another theory suggested that patients continuously wearing maxillary complete dentures and mandibular removable partial dentures eventually suffer from bone loss in the posterior mandible, thus the lower denture bases rotates downwards and a posterior open bite develops. During occlusion, a fulcrum axis is created in the upper denture at the first premolar region, where pressure is directed to the premaxilla and negative pressure on the posterior part of the palate and ridge. As a result, hypertrophy of posterior maxillary alveolar bone and tuberosities occurs to preserve the vertical occlusal relationship. ${ }^{(5)}$

Proper treatment planning is mandatory to prevent the degenerative changes that occur in the combination syndrome. ${ }^{(4)}$ Efforts should be made to avoid the destructive occlusal forces exerted on the anterior part of the maxilla. Implant rehabilitation techniques have been proposed for patients at risk of developing combination syndrome to allow bone preservation, reduction of anterior occlusal trauma and reestablishment of posterior occlusion. ${ }^{(5)}$

Implant-retained overdentures gain their support, retention, and stability from both the implants and tissues thus fewer implants can be used in comparison to fixed implant prostheses. Four implants are the minimum number needed for maxillary overdenture treatment with full palatal coverage and proper extensions of the denture bases. The number and position of the implants used depends on several factors which include: the quality of bone in the maxilla, the condition of the opposing arch and occlusal forces, the type and number of attachments, the inter arch distance, the shape of the residual ridge, arch form, and implant angulation. ${ }^{(6)}$ The alveolar bone quantity influences many factors in the implant treatment planning, such as bone augmentation, implant type, length, and installation angle. On the other hand, the bone quality is also important as it influences the stability 
of implants. Therefore, a proper assessment of these factors is important in treatment planning for implants. ${ }^{(7-9)}$

Patients with large edentulous spaces are commonly rehabilitated with removable partial dentures. The difference between the resiliency of the oral mucosa and periodontal ligament of the abutments affects the outcome of removable partial dentures (RPD) for free-end saddle cases. Dissatisfaction of the patients with distal extension RPD is mainly due to poor retention and food impaction under the denture bases. ${ }^{(10)}$ It has been recommended to insert two distal implants to transform Kennedy class I to a Kennedy class III to simplify the RPD design. (11) Moreover, studies showed that implants maintain the vertical dimension of occlusion and reduce bone resorption commonly occurring in patients wearing distalextension removable dentures. ${ }^{(12,13)}$

The evaluation of the amount of bone loss of the alveolar bone is a vital step for pre-surgical and post-surgical implant placement, evaluation and follow-up. (14) Cone-beam computerized tomography (CBCT) imaging can be used to assess volumetric changes in different time intervals. Thus, this technique is commonly used for diagnosis, treatment planning, patient follow-up and research in the maxillofacial region. ${ }^{(15,16)} \mathrm{CBCT}$ provides non-invasive technique to consistently record images and measurements of the palatal mucosa. It is a reliable, simple and reproducible technique useful in implant planning and other oral surgeries. ${ }^{(17)}$

Several studies have suggested the relation between implant supported mandibular and maxillary overdentures and the prevention of combination syndrome, hence this study was conducted to determine whether mandibular implant supported or maxillary implant supported overdenture is more effective.

\section{MATERIALS AND METHODS}

Fourteen patients were selected from the outpatient clinic of the Prosthodontics Department, Faculty of Dentistry, Ain Shams University to participate in this study. Inclusion criteria: patients with completely edentulous upper arch and mandibular bilateral distal extensions (Kennedy class I) with the canines or first premolar as the last standing tooth. Patients had well-formed residual ridge covered with dense fibrous connective tissue, Angle class I ridge relationship, and adequate inter arch space. Exclusion criteria: patients with systemic diseases that might affect the oral tissues or bone, neuromuscular disorders, temporomandibular joint disorders and smokers.

Intraoral examination included visual and digital assessment of oral hygiene and clinical condition of remaining teeth and residual ridge. Cone Beam CT was taken to detect the presence of any pathological lesions, cysts or remaining roots in the lower ridge, to evaluate the condition of the abutments and to determine the approximate bone width and height at the proposed implant site.

Upper complete dentures and lower acrylic removable partial denture were constructed to all the patients following the same basic principles. Centric occlusion was developed at centric relation. Modified cusped acrylic teeth were used and balanced on semi-adjustable articulator for centric and eccentric positions following the lingualized concept of occlusion.

Patients participating in this study were randomly divided into two equal groups: Group I: patients were rehabilitated with mucosa supported maxillary complete denture and lower tooth-implant partial denture retained by two osseointegrated implants on each side of the lower arch in the first molar area and RPI direct retainer. Group II: patients were rehabilitated with implant retained and supported maxillary complete overdenture by four 
osseointegrated implants in the anterior maxillary area and tooth-tissue supported partial denture retained by RPI direct retainer.

1) Construction of mucosa supported maxillary complete denture and lower toothimplant partial denture retained by two osseointegrated implants and RPI direct retainer (group I):

Two implants were placed in the lower first molar region. The Pitt-Easy color guided implant system V-TPS (Vacuum-Titanium Plasma Spray) coating root form, cylindrical screw, internally hexed titanium implants and self-tapping expansion thread system were used (Syborn Implant Solutions Pitt- Easy implant system, Germany). They are available in five diameters and five lengths ranging from 8 to $16 \mathrm{mms}$. The implant length and diameter were selected according to available bone detected from the pre-operative cone-beam computerized tomography. The implant is sterilized with gamma rays in a double pack with its titanium covering screw included. A crestal incision was made and the flap was elevated. The surgical stent was seated in the patient's mouth to identify the exact area for implant insertion. The bone site was prepared following the drill sequence recommended by the implant manufacturer. The direction of the preparation was made parallel to the distal surface of the last abutment (according to the selected path of insertion). The implant was threaded into the bone in a clockwise direction until its top flushed with the bone surface by help of ratchet then the flap was replaced.

A three months period was allowed before construction of removable partial denture to allow for osseo-integration in which patients used their acrylic dentures. Three months after implant placement, the patient was recalled and the top of the implant was exposed with a tissue punch, the cover screw was removed and the selected abutment (ball head abutment) was inserted.
Lower partial dentures were constructed following the basic principles to be in harmony with the pre-constructed maxillary complete dentures. Primary impression was made for all patients and poured into stone cast. The lower study cast was preliminary surveyed to determine the path of insertion and removal, and the needed mouth preparation. The mouth preparations required, as drawn on the surveyed lower study cast, mesial rest seats and distal guiding planes were prepared on each abutment tooth adjacent to the edentulous areas, extended cingulum rest seat preparation was prepared on the lingual surface of the canine when the last standing abutments were first premolar were carried out. Secondary impression was made while the O-ring metal housing was placed on the ball head abutment. Ready-made wax pattern was used to fabricate the partial denture framework. The bilateral denture base meshworks were spaced around the position of the O-ring metal housing. The framework was cast in Cobalt-Chromium alloy. Metallic framework was verified in the patient's mouth while the O-ring metal housing was in position. Centric occluding relation was recorded using the wax wafer technique. Modified crosslinked acrylic teeth were used and balanced on semi-adjustable articulator for centric and eccentric positions following the lingualized concept of occlusion. Patients were recalled after one week for clinical remounting and occlusal adjustments to eliminate occlusal interferences and provide free gliding from centric to eccentric jaw positions. The fitting surface of the acrylic resin of the denture base over the implant was relieved to allow fitting the O-ring metal housing in its position. Pink wax was used to block the undercut portion of the neck of the ball head abutment then auto polymerizing pink acrylic resin was placed to pick up the metal housing. (Fig. 1) 


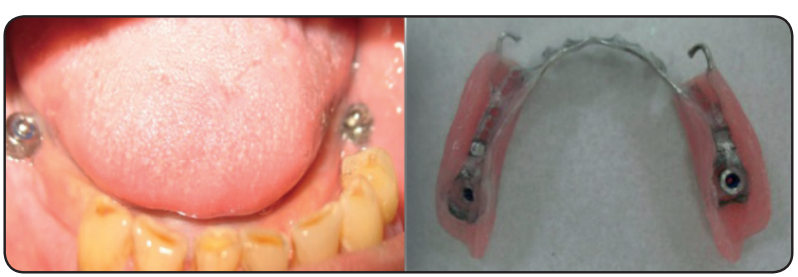

Fig (1) Implant and O-ring in proper position

2) Construction of implant retained and supported maxillary complete overdenture by four osseointegrated implants in the anterior maxillary area and tooth-tissue supported partial denture retained by RPI direct retainer. (group II):

Upper and lower dentures were constructed following the same procedures and techniques performed for group I patients. The radiographic diagnostic stent was modified by installing four holes at the predetermined implant sites. An incision was placed in midcrestal position to elevate full-thickness flaps. The incision extended from the distal end of the incisive papilla backward till the premolar area with two releasing incisions. Implants insertion procedures were performed as for group I patients. Four implants were installed in anterior maxillary area.

The implants were left in a submerged position for 4 months then they were exposed and the selected abutments (ball head abutments) were inserted. Areas in the upper denture corresponding to the inserted ball abutments were marked on the fitting surface of the denture and relieved. The O-ring attachments were placed on the abutments

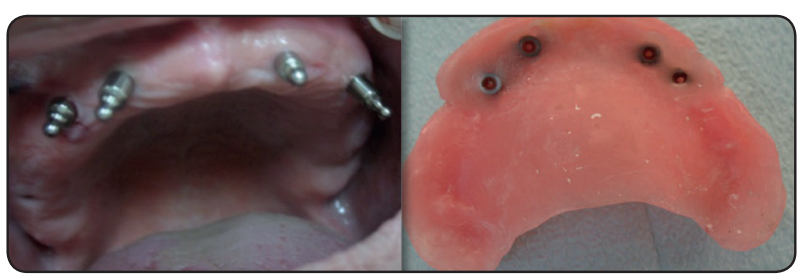

Fig (2) Implant \& O-ring in proper position and incorporated directly on the denture base with auto polymerizing resin while the patient closed in centric occlusion. (Fig. 2)

\section{Outcome assessed}

\section{a-Radiographic evaluation:}

Bone height was carried on using liner measurement system supplied with cone beam CT. Bone height at anterior maxillary region was measured at three points (midline and $1 \mathrm{~cm}$ distal to midline on both sides). Midline was located at center of incisive foramen at axial view. Bone height measurements for group II were recorded at mid line and inter implant area. The marginal bone loss at different intervals was obtained by calculating the difference in bone height at that interval from the baseline measurement. The measurements were carried out at the end of each follow-up appointment (at insertion, 6, and 12 ,18months post insertion). (Fig 3)

\section{b-Measurement of mucosal thickness:}

Mucosal thickness was measured at crest of maxillary ridge at three points (midline, $1 \mathrm{~cm}$ distal to midline on both side). Midline was located at center of incisive papilla. For group II mucosal thickness was measured at crest of maxillary ridge at three points midline and mid implant area on both side. The patient was asked to rinse with $0.1 \%$ chlorhexidine mouthwash. Infiltration anesthesia was given to the patient at the proposed sites.The thickness of mucosa was estimated using periodontal probe with a rubber stopper. At the proposed measurement sites, a sterile probe with file stopper was used to puncture the mucosa at crest of ridge. (Fig 3). Thickness of mucosa at different sites was calculated and average of these measurement was calculated and recorded.

\section{Statistical analysis}

Data management and analysis were performed using Statistical Analysis Systems. SPSS software (version 13.1: SPSS Inc). Probability values $\leq 0.05$ to 


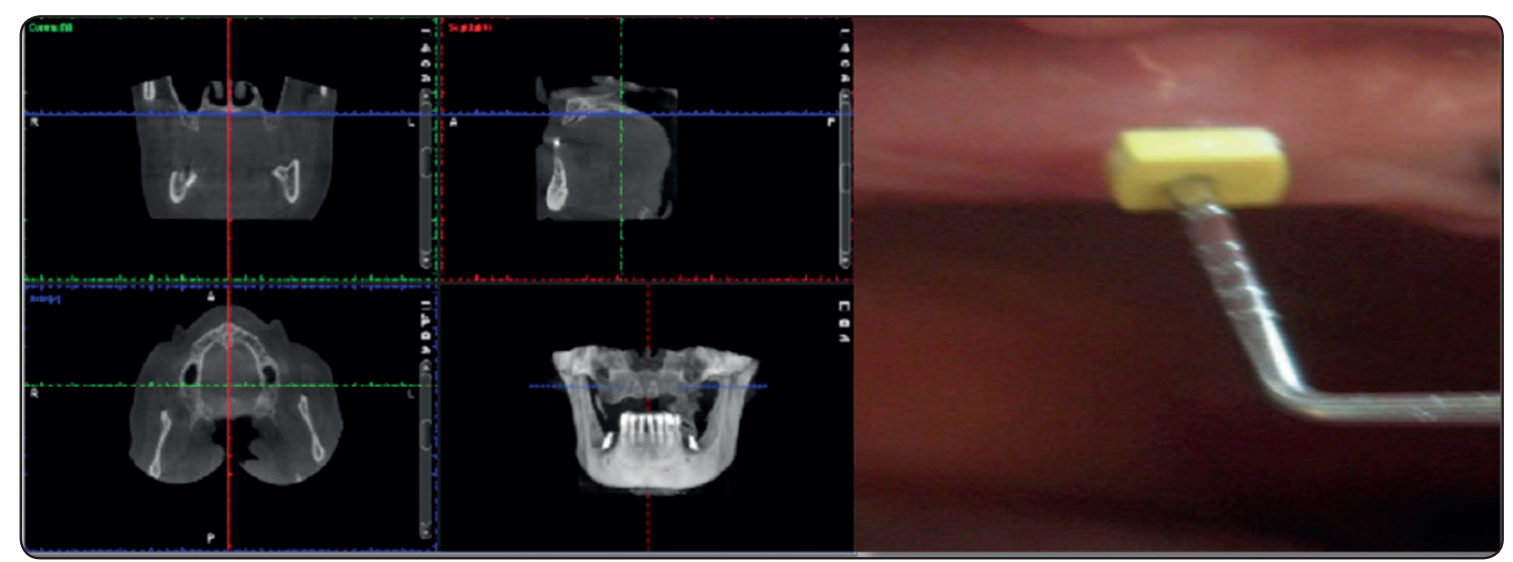

Fig (3) Measurement system supplied with cone beam\& measurement of mucosal thickness

indicate significant relationships between variables. Shapiro-Wilk tests was used to assess data normality and showed normal distribution. Data were summarized using means and standard deviations. Mixed Anova test was used for comparison between groups and between follow up periods followed by simple main effect with Bonferroni corrections. Results were represented in tables (1-3)

\section{RESULTS}

Statistical analysis of bone height using mixed Anova test for repeated measures revealed significance difference $(\mathrm{P} \leq 0.05)$ in bone height between follow up periods. Simple main effect with Bonferrioni correction revealed significant difference between bone height at denture insertion and bone height 18 months and between bone height at 6 months and bone height at 18 months. Regarding statistical analysis of mucosal thickness revealed significance difference between follow up periods. Simple main effect with Bonferrioni correction revealed signifcant difference between mucosal thickness at denture insertion and mucosal thickness at 12 months and 18 months.
TABLE (1) Mean and standard deviation values of bone height, and mucosal thickness at different follow up periods at group I

\begin{tabular}{|c|c|c|c|c|}
\hline & $\begin{array}{c}\text { Denture } \\
\text { insertion }\end{array}$ & 6 months & $\begin{array}{c}12 \\
\text { months }\end{array}$ & $\begin{array}{c}18 \\
\text { months }\end{array}$ \\
\hline $\begin{array}{c}\text { Bone } \\
\text { height }\end{array}$ & $11 \pm 0.6^{\mathrm{a}}$ & $10.8 \pm 0.4^{\mathrm{a}}$ & $10.7 \pm 0.2^{\mathrm{ab}}$ & $10.5 \pm 0.3^{\mathrm{b}}$ \\
\hline $\begin{array}{c}\text { Mucosal } \\
\text { thickness }\end{array}$ & $2.3 \pm 0.3^{\mathrm{a}}$ & $2.5 \pm 0.3^{\mathrm{ab}}$ & $2.8 \pm 0.27^{\mathrm{b}}$ & $2.9 \pm 0.22^{\mathrm{b}}$ \\
\hline
\end{tabular}

TABLE (2) Mean and standard deviation values of bone height, and mucosal thickness at different follow up periods at group II

\begin{tabular}{|c|c|c|c|c|}
\hline & $\begin{array}{c}\text { Denture } \\
\text { insertion }\end{array}$ & 6 months & $\begin{array}{c}12 \\
\text { months }\end{array}$ & $\begin{array}{c}18 \\
\text { months }\end{array}$ \\
\hline $\begin{array}{c}\text { Bone } \\
\text { height }\end{array}$ & $10.9 \pm 0.7^{\mathrm{a}}$ & $10.7 \pm 0.9^{\mathrm{ab}}$ & $10.5 \pm 0.8^{\mathrm{ab}}$ & $10.4 \pm 0.9^{\mathrm{b}}$ \\
\hline $\begin{array}{c}\text { Mucosal } \\
\text { thickness }\end{array}$ & $2.2 \pm 0.3^{\mathrm{a}}$ & $2.4 \pm 0.2^{\mathrm{a}}$ & $2.5 \pm 0.4^{\mathrm{a}}$ & $2.5 \pm 0.2^{\mathrm{a}}$ \\
\hline
\end{tabular}

As confirmed in table 2, statistical analysis of bone height using mixed Anova test revealed significance difference $(\mathrm{P} \leq 0.05)$ in bone height at denture insertion \& 18 months. Although the data obtained from table 2 revealed increase in the 
amount of mucosal thickness during the follow up period, statistical analysis of the data revealed insignificance difference in mucosal thickness between follow up periods.

TABLE (3): Mean and standard deviation values of studied groups regarding change in bone height, and mucosal thickness from denture insertion to 18 months between studied groups

\begin{tabular}{|c|c|c|}
\hline & Group I & Group II \\
\hline Bone height & $0.5 \pm 0.2$ & $0.5 \pm 0.2$ \\
\hline Mucosal thickness & $0.6 \pm 0.3$ & $0.3 \pm 0.2$ \\
\hline
\end{tabular}

The mean values of changes in bone height at anterior maxillary region were $0.5 \mathrm{~mm}$, and $0.5 \mathrm{~mm}$ for group I, and group II respectively. The mean values of changes in mucosal thickness at premaxilla were $0.6 \mathrm{~mm}$, and $0.3 \mathrm{~mm}$ for group I, and group II. Group II showed decrease in bone loss in height and decrease in mucosal thickness compared to group I however difference between groups were statistically insignificant.

\section{DISCUSSION}

Prosthetic rehabilitation of edentulous maxilla opposed by natural mandibular anterior teeth is one of the most complex problem in removable prostheses. The specific destructive oral changes encountered in those patients are known as combination syndrome. Several treatment modalities have been suggested to prevent the development of combination syndrome. One approach to minimize occlusal stresses involves the use of tooth-implant supported and retained mandibular partial denture. Theoretically, implant located posteriorly provides maximum support and stabilize the denture base in a vertical direction, provides stable posterior occlusion, and minimize occlusal pressures on the anterior maxilla. ${ }^{(18)}$ Another approach to minimize the undesirable forces transmitted to the anterior maxillary segment, involves the use of implant retained and supported maxillary overdenture. The use of implants installed in the anterior maxillary segment improves propriception, reduces trauma to the underlying tissues, thereby reduces bone resorption and attains more patient tolerance. ${ }^{(19)}$ Accordingly, this study was attempted to assess and compare the effect of different treatment modalities on prevention of combination syndrome by measuring bony changes in the anterior maxilla and thickness of the masticatory mucosa. ${ }^{(20)}$

In comparison to the results obtained by Kelly ${ }^{(4)}$ the results of this studiy revealed marked decrease in the amount of crestal bone loss. Kelly in a threeyears longitudinal study observed bone loss of $1.35 \mathrm{~mm}$ in patients rehabilitated with upper single denture opposing distal extension removable partial denture Results of this study showed decrease in bone height in the two groups over 18 months (0.5 $\mathrm{mm}$ for group I, and $0.5 \mathrm{~mm}$ for group II) and this was lower than bone loss observed by Kelly (1.35 mm over three years).

There was increase in thickness of mucosa in all groups over 18 months $(0.6 \mathrm{~mm}$ for group I, and $0.3 \mathrm{~mm}$ for group II) however difference was statistically insignificant between groups. Increase in thickness of mucosa may be due normal healing process after extraction of teeth as reported by Iasella et al. ${ }^{(21)}$ demonstrated a $0.4-0.5 \mathrm{~mm}$ gain of soft tissue thickness at 6 months.

In the present study, although evaluation of maxillary bone height and thickness of the mucoperiosteum showed that maxillary implant retained overdenture provided more satisfactory results, there were no significant difference between groups regarding change in bone height and mucosal thickness at premaxillay region compared to the other studied groups. Since occlusal loading 
is implicated in crestal bone loss, the insignificant changes in measured bone loss in the studied groups may be attributed to the established occlusal scheme which distributes occlusal forces to the supporting structures of the non-working side and minimizes force transmission to the premaxillary region. Functionally, there was no anterior contact in centric, with light contact during excursive mandibular movement. In addition, lingualized occlusal concept minimizes the amount of lateral or horizontal forces being transmitted to the ridge. Both Saunders et al ${ }^{(3)}$ and Schmitt ${ }^{(22)}$ believed that the anterior teeth of all maxillary complete dentures be used only for cosmetic and phonetic purposes, keeping excursive contact to a minimum.

The slight measured maxillary bone resorption detected in patients rehabilitated by implant and mucosa supported maxillary complete denture and tooth-tissue supported partial denture retained that was evident throughout the study period compared to the other studied groups was supported by the findings of Tolstunov ${ }^{(19)}$, who recommended the use of dental implant $\mathrm{s}$ in maxilla as treatment option for prevention of combination syndrome. The use of implant improves the upper denture retention and dentures enhances proprioception. It reduces trauma to the underlying tissues, and the subsequent maxillary resorption and could account for this finding.

Although mandibular bone loss was not evaluated in this study, clinical studies ${ }^{(23,24)}$ have shown that tooth -implant supported mandibular partial denture leads to significant improvement of bone loss compared to tooth tissue mandibular partial denture. Placement of two implant in lower free end saddle area provide better support for lower denture and help in maintaining posterior occlusal contact and no occlusal contact in anterior region. Loss of posterior contact caused a change in the angulation of the occlusal plane and unfavorable loading to the anterior maxillary ridge and subsequent bone resorption.

\section{CONCLUSION}

Within the limitations of the number of studied patients and follow up period of this study it could be concluded that, preventing the degenerative oral changes that occurs when complete maxillary dentures opposes the Kennedy class I partial dentures may be possible through accurate treatment planning and, the development of stable posterior occlusion that controls of occlusal pressures on the anterior maxilla. Also, maxillary implant retained overdentures should be considered preferable treatment option, whenever the available bone quantity and quality permits.

\section{REFERENCES}

1- Oral implantology. Glossary of implant terms. J Oral Implantol, 2007. Suppl 1: p. 2-14.

2- Academy of Prosthodontics. Glossary of prosthodontic terms. . J Prosthet Dent, 2005. 94: p. 10

3- Saunders T.R., Gillis R.E., Jr., and Desjardins, R.P.: The maxillary complete denture opposing the mandibular bilateral distal-extension partial denture: treatment considerations. J Prosthet Dent, 1979. 41(2): p. 124-8.

4- Kelly, E.: Changes caused by a mandibular removable partial denture opposing a maxillary complete denture. J Prosthet Dent, 1972. 27(2): p. 140-50.

5- Tolstunov, L.: Combination syndrome symptomatology and treatment. Compend Contin Educ Dent, 2011. 32(3): p. 62-6.

6- Jivraj, S., Chee, W., and Corrado, P.: Treatment planning of the edentulous maxilla. Br Dent J, 2006. 201(5): p. 261-79; quiz 304.

7- de Oliveira, R.C., Leles, C.R., Normanha, L.M., Lindh, C., and Ribeiro-Rotta, R.F.: Assessments of trabecular bone density at implant sites on CT images. Oral Surg Oral Med Oral Pathol Oral Radiol Endod, 2008. 105(2): p. 231-8.

8- Roze, J., Babu, S., Saffarzadeh, A., Gayet-Delacroix, M., Hoornaert, A., and Layrolle, P.: Correlating implant stability to bone structure. Clin Oral Implants Res, 2009, 20(10): p. $1140-5$.

9- Wakimoto, M., Matsumura, T., Ueno, T., Mizukawa, N., Yanagi, Y., and Iida, S.: Bone quality and quantity of the 
anterior maxillary trabecular bone in dental implant sites. Clin Oral Implants Res, 2011.

10- de Carvalho, W.R., Barboza, E.P., and Caula, A.L.: Implant-retained removable prosthesis with ball attachments in partially edentulous maxilla. Implant Dent, 2001. 10(4): p. 280-4.

11- Shahmiri, R.A. and Atieh, M.A.: Mandibular Kennedy Class I implant-tooth-borne removable partial denture: a systematic review. J Oral Rehabil, 2010. 37(3): p. 225-34.

12- Kaufmann, R., Friedli, M., Hug, S., and Mericske-Stern, R.: Removable dentures with implant support in strategic positions followed for up to 8 years. Int $\mathrm{J}$ Prosthodont, 2009. 22(3): p. 233-41; discussion 242.

13- Zitzmann, N.U., Sendi, P., and Marinello, C.P.: An economic evaluation of implant treatment in edentulous patients-preliminary results. Int J Prosthodont, 2005. 18(1): p. 20-7.

14- Norton, M.R. and Gamble, C.: Bone classification: an objective scale of bone density using the computerized tomography scan. Clin Oral Implants Res, 2001. 12(1): p. 79-84.

15- Scarfe, W.C., Farman, A.G., and Sukovic, P.: Clinical applications of cone-beam computed tomography in dental practice. J Can Dent Assoc, 2006. 72(1): p. 75-80.

16- Sukovic, P.: Cone beam computed tomography in craniofacial imaging. Orthod Craniofac Res, 2003. 6 Suppl 1: p. 31-6; discussion 179-82.

17- Barriviera, M., Duarte, W.R., Januario, A.L., Faber, J., and Bezerra,A.C.: A new method to assess and measure palatal masticatory mucosa by cone-beam computerized tomography. J Clin Periodontol, 2009. 36(7): p. 564-8.
18- Keltjens, H.M., Kayser, A.F., Hertel, R., and Battistuzzi, P.G., Distal extension removable partial dentures supported by implants and residual teeth: considerations and case reports. Int J Oral Maxillofac Implants, 1993. 8(2): p. 208-13.

19- Tolstunov, L., Combination syndrome: classification and case report. J Oral Implantol, 2007. 33(3): p. 139-51.

20- Jameson, W.S., Combining fixed and removable restorations with linear occlusion to treat combination syndrome: a clinical report. Gen Dent, 2004. 52(2): p. 135-41.

21- Iasella, J.M., Greenwell, H., Miller, R.L., Hill, M., Drisko, C., Bohra, A.A., and Scheetz, J.P., Ridge preservation with freeze-dried bone allograft and a collagen membrane compared to extraction alone for implant site development: a clinical and histologic study in humans. J Periodontol, 2003. 74(7): p. 990-9.

22- Schmitt, S.M., Combination syndrome: a treatment approach. J Prosthet Dent, 1985. 54(5): p. 664-71.

23- Kreisler, M., Behneke, N., Behneke, A., and d'Hoedt, B., Residual ridge resorption in the edentulous maxilla in patients with implant-supported mandibular overdentures: an 8-year retrospective study. Int J Prosthodont, 2003. 16(3): p. 295-300

24- Wright, P.S., Glantz, P.O., Randow, K., and Watson, R.M., The effects of fixed and removable implant-stabilised prostheses on posterior mandibular residual ridge resorption. Clin Oral Implants Res, 2002. 13(2): p. 169-74. 